Indigenous Peoples, COVID-19, and WCS Canada's Response: Protecting People and Rights

It is now over two months since COVID-19 was declared a pandemic creating changes to societies around the world. In Canada, public health measures to deal with COVID-19 and responses by governments including social distancing, school and business closures, and limits to civil liberties. These responses have created uncertainty and exposed vulnerabilities in our social and ecological systems. Indigenous Peoples in Canada are disproportionately affected by both COVID-19 and government measures to mitigate the spread.

While working from home, WCS Canada staff support Indigenous Peoples in the best way we can including: respecting community priorities on health and self-isolation; supporting First Nations responsibilities and rights to take care of the land; and, amplifying food sovereignty, particularly traditional and country foods.

\title{
Health
}

It is widely acknowledged that Indigenous Peoples are more likely than other Canadians to experience severe health outcomes as a result of COVID-19 due to pre-existing health issues, substandard infrastructure, and a lack of clean drinking water and medical supplies. These are long-standing issues due to failures in federal and provincial governments to support the health and wellbeing of Indigenous Peoples. First Nation and Inuit communities are in self-isolation and have restricted non-residents from entering their communities. Calls for comprehensive pandemic prevention and response plans, especially for remote communities, have not materialized while funding is limited, and communities face numerous barriers to addressing health and safety in their communities. Respecting these measures, WCS Canada has postponed or is adapting existing research with First Nations and continues to support First Nations and the Inuvialuit involved in community-based monitoring projects in northern Ontario and the Inuvialuit Settlement Region, respectively.

\section{Responsibilities and Rights}

\section{IPCAs}

Indigenous Peoples have been taking care of the land since time immemorial and their ways of knowing, doing, and being support the biodiversity that many of us, including WCS Canada, value today. In Canada, Indigenous Peoples have a primary role in protecting and conserving the land, waters, fish, and wildlife through Indigenous knowledge systems and the creation of Indigenous Protected and Conserved Areas (IPCAs). IPCAs draw on the best of Indigenous knowledge and science (see also Indigenous Guardians) to support local solutions in response to COVID-19. IPCAs are providing social and ecological resilience and refuge in the face of current crises such as climate change, biodiversity loss, and COVID19. IPCAs are also an opportunity for non-Indigenous societies to consider our relationships with nature and our responsibilities toward animals given the origins of the current pandemic. WCS Canada has been providing technical expertise and support for First Nations developing IPCAs in northern Ontario, Yukon, and northern British Columbia and we continue to do this work virtually while working to transform conservation practice to support IPCAs in Canada. 


\section{Impact Assessment}

- In the face of the limited funding from governments to support First Nations response to COVID19, Matawa First Nation Chiefs asked, "Where are the partners who want to extract billions in resources from our territory now?" While Ontario and Canada have been engaged with First Nations to develop multiple roads to the Ring of Fire, COVID-19 exposes the need for a rigorous and comprehensive regional impact assessment that can consider the biophysical, social, cultural, and health impacts of opening up this intact and globally significant region, including the cumulative social impacts on First Nations dealing with chronic underfunding, lack of capacity, and suppression of governance in the face of historic and ongoing colonialism. WCS Canada is an interested party in the regional assessment in the Ring of Fire, which we have worked to make the case for since 2014. The federal government is currently unable to engage meaningfully with First Nations and the public on this process.

- First Nations in the Yukon are engaged in a number of regional and sub-regional planning processes as part of their responsibilities and rights to take care of the lands, waters, and wildlife. WCS Canada continues to support the conservation priorities and values of First Nations where land use planning processes are occurring, including Tr'ondëk Hwëch'in and the Dawson Regional Land Use Plan, and the First Nation of Na-cho Nyäk Dun and the sub-regional Beaver River Land Use Plan (BRLUP). While First Nations remain committed to protecting their lands and rights, regardless of the challenges posed by the pandemic, a number of mining proposals and impact assessment processes are continuing. This is forcing some Nations, including the First Nation of $\mathrm{Na}$-cho Nyäk Dun, to request suspending their engagement in planning in the face of prioritizing the protection of their communities from the potentially devastating impacts of COVID-19. WCS Canada supports these decisions and calls on the Crown to act honourably towards First Nations by providing equitable access to health care and supports while also ensuring development does not proceed without meaningful engagement with impacted communities.

\section{Food Insecurity and Food Safety}

Indigenous Peoples have dynamic relationships with the land, waters, plants, fish, and wildlife. Harvesting nutritionally and spiritually valuable plants, fish, and wildlife from the land, water, and sky continues to be a necessary and important part of the lives, identity, rights, and responsibilities of First Nations, Inuit, and Métis. Relationships and knowledge systems of traditional and country foods are the foundation of Indigenous food sovereignty and food security.

While COVID-19 did not cause food insecurity, it exposes the serious issues in our relationships with domestic and wild animals in a global economy and highlights the connectivity of human societies that exposes Indigenous Peoples to new diseases. Indigenous Peoples in northern Canada do have concerns about food safety. These include the complex risks associated with eating traditional and country foods given the nutritional value and safety of store-bought, or market foods. Traditional and country foods remain an important enabler of health and wellness and programs that support on-the-land activities and Indigenous knowledge systems. Sharing wild foods strengthens food security -- even as government responses reinforce paternalism and inequities. WCS Canada is working in Ontario to better understand contaminant levels in northern fishes and preparing a report on zoonotic diseases and monitoring needs in the Arctic and boreal. 